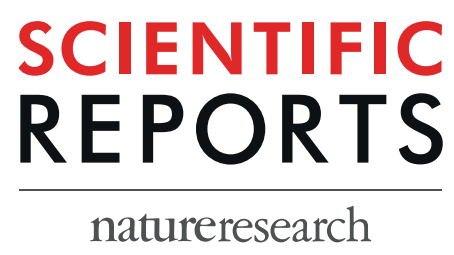

\title{
OPEN Protective effects of seaweed supplemented diet on antioxidant and immune responses in European seabass (Dicentrarchus labrax) subjected to bacterial infection
}

\begin{abstract}
Maria J. Peixoto ${ }^{1,2}$, Renato Ferraz ${ }^{1,2}$, Leonardo J. Magnoni $\mathbb{1}^{1,5}$, Rui Pereira ${ }^{3}$, José F. Gonçalves ${ }^{2}$, Josep Calduch-Giner ${ }^{4}$, Jaume Pérez-Sánchez ${ }^{4}$ \& Rodrigo O. A. Ozório ${ }^{1,2 *}$

European seabass (Dicentrarchus labrax) production is often hampered by bacterial infections such as photobacteriosis caused by Photobacterium damselae subsp. piscicida (Phdp). Since diet can impact fish immunity, this work investigated the effect of dietary supplementation of $5 \%$ Gracilaria sp. aqueous extract (GRA) on seabass antioxidant capacity and resistance against Phdp. After infection, mortality was delayed in fish fed GRA, which also revealed increased lysozyme activity levels, as well as decreased lipid peroxidation, suggesting higher antioxidant capacity than in fish fed a control diet. Dietary GRA induced a down-regulation of hepatic stress-responsive heat shock proteins ( $g r p-78$, grp-170, grp94, grp-75), while bacterial infection caused a down-regulation in antioxidant genes ( $p r d \times 4$ and $m n$ sod). Diet and infection interaction down-regulated the transcription levels of genes associated with oxidative stress response ( $p r d \times 5$ and $g p \times 4$ ) in liver. In head-kidney, GRA led to an up-regulation of genes associated with inflammation (il34, ccr9, cd33) and a down-regulation of genes related to cytokine signalling ( $m i f, i l 1 b$, defb, a2m, myd88). Additionally, bacterial infection up-regulated immunoglobulins production (IgMs) and down-regulated the transcription of the antimicrobial peptide leap 2 in head kidney. Overall, we found that GRA supplementation modulated seabass resistance to Phdp infection.
\end{abstract}

Aquaculture production involves rearing animals at high densities in enclosed spaces, often resulting in deteriorated water quality, affecting fish health and favouring the proliferation of opportunistic bacteria ${ }^{1,2}$. These conditions lead to immunosuppression and the disruption of antioxidant systems, increasing the susceptibility to infectious agents ${ }^{3}$. A common opportunist is the Gram-negative halophilic bacterium Photobacterium damselae subsp. piscicida (Phdp), the causative agent of photobacteriosis. This fish disease is known to induce acute septicaemia in young fish or granulomatous lesions in adults ${ }^{4}$ culminating in high mortality rates and massive economic losses for producers ${ }^{2}$. To address this issue, producers favour preventive techniques ${ }^{5}$, such as strengthening fish immunity through the prophylactic administration of immunostimulants and antioxidant supplements ${ }^{6}$. These cost effective and sustainable methods constitute an alternative to vaccines, maximizing the use of natural components in diets formulation, as they are less likely to interfere with fish homeostasis or disrupt the environment $t^{5,7}$. Thus, seaweeds containing bioactive molecules with immunostimulant and antioxidant properties are in the spotlight to improve robustness of farmed fish without compromising growth ${ }^{9,10}$.

The polysaccharides of seaweeds have been shown to stimulate non-specific host immunity and to inhibit bacterial activity. These carbohydrates also positively modulate gut health and potentiate fish digestive capacities,

\footnotetext{
${ }^{1}$ CIIMAR - Centro Interdisciplinar de Investigação Marinha e Ambiental, Universidade do Porto, Av. General Norton de Matos s/n, 4450-208, Matosinhos, Portugal, Portugal. ${ }^{2}$ ICBAS - Instituto de Ciências Biomédicas de Abel Salazar, Universidade do Porto, Rua de Jorge Viterbo Ferreira 228, 4050-313, Porto, Portugal. ${ }^{3}$ ALGAPLUS, Lda - Travessa Alexandre da Conceição S/N, 3830-196, Ílhavo, Portugal. ${ }^{4}$ Nutrigenomics and Fish Growth Endocrinology Group, Institute of Aquaculture Torre de la Sal, IATS-CSIC, 12595, Ribera de Cabanes, Castellón, Spain. ${ }^{5}$ IIB-INTECH - Instituto de Investigaciones Biotecnológicas - Instituto Tecnológico de Chascomús (CONICET), Chascomús, Argentina. *email: rodrigo.ozorio@ciimar.up.pt
} 
hallmarks of a prebiotic categorization ${ }^{10-12}$. Additionally, seaweed $\beta$-glucans were described to stimulate the immune system through the rapid release of reactive oxygen species (ROS) and signalling proteins ${ }^{13}$. Seaweed phenolic compounds may also wield a scavenging effect $^{14}$, reducing ROS formation in fish tissues. Moreover, red seaweeds such as Gracilaria sp. are rich in arachidonic acid, the precursor of the pro-inflammatory mediators prostaglandins, thromboxanes and leukotrienes ${ }^{15,16}$. These chemotactic lipids are key players in phagocytosis and antigen presentation ${ }^{17}$, essential to counteract infection.

The importance of European seabass (Dicentrarchus labrax) in aquaculture has instigated numerous studies regarding the effect of dietary changes in fish immunity, including the partial replacement of fish oil and fish meal ${ }^{18-20}$. However, long-term feeding with plant derived ingredients remains controversial due to anti-nutritional factors $^{21}$. For instance, diets with high soybean content, have been associated with the activation of $\mathrm{T}$ cell mediated processes such as the up-regulation of interleukins IL-18 and IL-22, as well as the transcription of genetic markers of inflammation, namely tumour necrosis factor (TNF- $\alpha$ ) and factor nuclear kappa (NF-kB) ${ }^{22}$. Despite the negative impact of plant proteins in fish health, these studies established that stress responsiveness and susceptibility to infection could be nutritionally modulated ${ }^{23}$. More recently, the supplementation of Gracilaria gracilis in Danio rerio diets resulted in increased immune and antioxidant activities ${ }^{24}$, yet little is known about the mechanisms by which functional foods modulate fish metabolism and immunity, both locally at infection sites and systemically ${ }^{25}$. Therefore, it is imperative for aquaculture to understand how ingredients derived from marine sources, such as seaweeds, can be used in aquafeeds to improve fish immunity.

The present work evaluated the effect of dietary supplementation with $5 \%$ Gracilaria sp. aqueous extract in seabass when infected with Photobacterium damselae subsp. piscicida. Specifically, we aimed to determine how Gracilaria sp. supplementation affected seabass survival rates, plasma bioindicators levels, immune and antioxidant parameters, as well as immune and antioxidant genes transcription in response to infection.

\section{Methods}

Study design. Seabass fingerlings were purchased from MARESA (Spain) and transported to the Aquatic Engineering laboratory of ICBAS (Porto, Portugal). Fish were then acclimated to the experimental conditions for two-weeks while fed the control diet. Afterwards fish were individually weighed (initial body weight: $11.95 \pm 0.34 \mathrm{~g}$ ) and distributed in eight circular tanks of $80 \mathrm{~L}$ capacity with 30 fish per tank. Four tanks were fed with the control diet and four with the diet containing 5\% supplementation with Gracilaria sp. For the first 80 days, tanks were connected to a closed recirculation seawater system ensuring similar quality parameters for all replicates. After this 80-day feeding period, all fish from 2 tanks from each diet (GRA or CTRL) were infected by injection with Phdp, whereas the fish from the 2 remaining tanks of each diet were administered a placebo injection. From inoculation time the tanks were individualized to prevent cross contamination. Water conditions were optimized and monitored daily to assure $30 \%$ salinity and $22 \pm 0.5^{\circ} \mathrm{C}$ temperature. A representation of the experimental design and the experimental units used in this study are summarized in Fig. S1.

Experimental diets. Two isoproteic (50\% DM) and isolipidic (19\%) diets were distributed in four replicate tanks: a control diet (CTRL) and a supplemented diet with 5\% Gracilaria sp. aqueous extract (GRA). The 5\% supplementation level was selected based on previous works from the authors ${ }^{26}$ and relevant publications in the field ${ }^{27,28}$. Gracilaria sp. was produced by ALGAPlus in a land based Integrated Multitrophic Aquaculture (IMTA) system $^{29}$. The seaweed was dried and thermally processed, using hot water at $83^{\circ} \mathrm{C}$ for $160 \mathrm{~min}$. After filtration, the resulting agar was recovered through a freeze-thawing process. The final solid product was washed, dehydrated with ethanol and dried at $60^{\circ} \mathrm{C}$ overnight under vacuum. The extract was then added as supplement to the experimental diet at $5 \% \mathrm{w} / \mathrm{w}$ base, adjusted for dry matter (DM) content. All ingredients were finely ground (hammer mill, $0.8 \mathrm{~mm}$ sieve), mixed and then extruded (twin screw extruder, $2.0 \mathrm{~mm}$ pellet size, SPAROS, Portugal). Diets were finally dried at $45^{\circ} \mathrm{C}$ for $12 \mathrm{~h}$ and stored at $4{ }^{\circ} \mathrm{C}$ until used. The detailed mineral and chemical compositions of the diets are presented in Table $\mathrm{S} 1$ of supplementary materials.

Bacterial suspension and dose validation. Photobacterium damselae subsp. piscicida (Phdp), strain SK-223/04, was purchased from CECT (Valencia, Spain). The strain was activated in tryptic soy broth (TSB; Biokar Diagnostics, France) and marine agar (Conda S.A., Spain). The bacteria were grown in TSB for $48 \mathrm{~h}$ at $22^{\circ} \mathrm{C}$ until reaching the exponential phase. The inocula were then centrifuged at $3500 \mathrm{~g}$, for $30 \mathrm{~min}$ at $22^{\circ} \mathrm{C}$ and the pellet resuspended in $\mathrm{NaCl} 0.9 \%$ (Sigma-Aldrich). From this initial suspension, serial dilutions were performed to establish a Phdp growth curve and calculate inocula concentration. These dilutions were spectrophotometrically measured at $600 \mathrm{~nm}$ and plated in marine agar (incubation for $48 \mathrm{~h}$ at $22^{\circ} \mathrm{C}$ ) to count the number of colony forming units (CFU) and correlate the CFU counts with bacterial turbidity.

A dose validation trial was performed to establish an appropriate concentration for the infection. Surplus seabass were randomly distributed in tanks (10 fish per tank), anesthetized by immersion in $0.5 \mathrm{ml}^{-1} \mathrm{l}^{-1}$ of 2-phenoxietanol (Sigma-Aldrich) and intraperitoneally (i.p.) injected with $100 \mu \mathrm{l}$ of saline solution (negative control) or Phdp suspension ( 3 test concentrations: $1.0 \times 10^{4}, 1.0 \times 10^{5}$ and $1.0 \times 10^{6} \mathrm{CFU} \mathrm{ml}^{-1}$ ). The survival rate was monitored for 7 days post-injection, which was the period that corresponded to the second consecutive day without mortalities. Samples were taken aseptically from the kidney of the infected fish, inoculated in marine agar plates and incubated 48 hours at $22^{\circ} \mathrm{C}$ for CFU counts.

The method described by Reed and Muench ${ }^{30}$ was used to calculate endpoints, although for ethical reasons concerning animal welfare guidelines, the concentration of the inocula for the bacterial infection was calculated to achieve a lethal dose (LD) of 30 to $40 \%$ efficiency.

Infection. After 80 days, 30 fish per tank from two replicate tanks fed on each of the diets were anesthetized and intraperitoneally injected with either a saline solution or Phdp suspension, similarly to the dose validation 
protocol described above. The Phdp inocula concentration was determined by absorbance (OD) as $5.93 \times 10^{6}$ CFU.ml ${ }^{-1}$.

For the following 10 days tanks were closely monitored to account for mortality and feed intake. Afterwards all fish were weighted and 10 fish per tank were selected based on apparent good health and normal swimming and feeding behaviours. These fish were anesthetized by immersion in $0.5 \mathrm{ml} . \mathrm{1}^{-1}$ of 2 -phenoxietanol (Sigma-Aldrich), blood was collected from the caudal vein and plasma obtained by centrifugation ( $5 \mathrm{~min}, 10000 \mathrm{~g}$ ), aliquoted and stored at $-80^{\circ} \mathrm{C}$. Liver, head kidney and spleen were also collected, and immediately frozen in liquid nitrogen and stored at $-80^{\circ} \mathrm{C}$. Fish body weight and feed intake were calculated for the entire experimental period using the tank as experimental unit. The following formula was used to calculate Voluntary feed intake: $100 \times[$ feed intake $(\mathrm{g}) / \mathrm{ABW}(\mathrm{g}) /$ trial duration (days), where $\mathrm{ABW}$ is $((\mathrm{IBW}+\mathrm{FBW}) / 2)$. FBW and IBW are the initial and final average body weights (g).

Plasma metabolites analysis. Plasma glucose (Glucose-RTU kit, Spinreact) and triglycerides (Triglycerides-LQ kit, Spinreact) concentrations were measured using $10 \mu \mathrm{L}$ of plasma and the commercial kits adapted to microplate format, according to the recommendations of the manufacturer. Samples ( 8 fish per tank, $\mathrm{N}=16$ ) were evaluated in duplicate and blanks were performed for standardization.

Immune plasma parameters. Immune parameters in plasma were assessed in 8 fish per $\operatorname{tank}(\mathrm{N}=16)$. Plasma lysozyme activity was evaluated by turbidimetric assay, according to Ellis ${ }^{31}$, based on the addition of the samples to a standard bacterial suspension of Micrococcus lysodeikicus. The absorbance decrease caused by bacterial lysis was measured by readings at $0.5 \mathrm{~min}$ and $4.5 \mathrm{~min}$ after addition. Values were standardized using hen egg white lysozyme (Sigma, Portugal). Plasma peroxidase levels were determined by the chemical reduction of 3,3, 5,5_- tetramethyl benzidine hydrochloride (Sigma, Portugal), according to Quade and Roth ${ }^{32}$.

Liver enzymatic assays. Livers were collected from 8 fish per $\operatorname{tank}(\mathrm{N}=16)$ and homogenised in phosphate buffer, $0.1 \mathrm{M} \mathrm{pH}$ 7.4. Part of the homogenates was used for analysis of thiobarbituric acid reactive substances (TBARS). The remaining portion was centrifuged at $10000 \mathrm{~g}$ for $20 \mathrm{~min}$ and supernatants used for analysis of protein content, catalase (CAT) and glutathione transferase (GST). Lipid peroxidation was measured by TBARS using methods described by Ohkawa, et al..$^{33}$ and results were reported as nmol. g tissue ${ }^{-1}$. The protein content of homogenates was measured using methods described by Bradford ${ }^{34}$. CAT activity was determined according to methods described by Clairborne ${ }^{35}$ with hydrogen peroxide (30\%) as substrate. GST activity was determined spectrophotometrically at $340 \mathrm{~nm}$ using 1-chloro-2,4-dinitrobenzene as substrate, according to the method described by Habig, et al. ${ }^{36}$. CAT and GST were reported as nmol. mg protein ${ }^{-1}$.

Gene expression analyses. After homogenization with TRI reagent, total RNA from target tissues (liver, head kidney and spleen, $\mathrm{N}=20$ ) was extracted with MagMax-96 for microarrays total RNA isolation kit (Life Technologies, Carlsbad, USA). RNA quantity and purity were determined by Nanodrop (Thermo Scientific) with absorbance ratios at $260 \mathrm{~nm} / 280 \mathrm{~nm}$ above 1.9. Reverse transcription (RT) of $500 \mathrm{ng}$ of total RNA was performed with random decamers, using the High-Capacity cDNA Archive Kit (Applied Biosystems, USA). RT reactions were incubated for $10 \mathrm{~min}$ at $25^{\circ} \mathrm{C}$ and $2 \mathrm{~h}$ at $37^{\circ} \mathrm{C}$. Real-time quantitative PCR (qPCR) was performed using an Eppendorf Mastercycler Ep Realplex Real-Time PCR Detection System (Eppendorf, Germany), using 96-well PCR array layouts designed for the simultaneous profiling of 19 genes in liver (Table S3) and 29 genes in head kidney and spleen (Table S4).

Genes selected for analysis in the liver were focused on oxidation-reduction processes, cell redox homeostasis, response to oxidative stress and cellular respiration. Genes selected for immune response evaluation in head kidney and spleen were involved in response to bacterium, cytokine-cytokine receptor interaction, cytokine signalling, response to cytokines and cell proliferation. Primers were designed to obtain amplicons of 50-150 bp in length. The arrays included 23 new sequences for seabass, already represented in the IATS-nutrigroup seabass transcriptomic database (www.nutrigroup-iats.org/seabass $\mathrm{db}^{37}$ ) and deposited in GenBank with the accession numbers MG596338-MG596342, MG596345, MH138003-MH138019 (Table S5). Among them, 16 are full codifying sequences. The PCR program used included an initial denaturation step $\left(95^{\circ} \mathrm{C}\right.$ for $\left.3 \mathrm{~min}\right)$, followed by 40 cycles of denaturation $\left(15 \mathrm{~s}\right.$ at $\left.95^{\circ} \mathrm{C}\right)$ and annealing/extension for $60 \mathrm{~s}$ at $60^{\circ} \mathrm{C}$. All pipetting operations were performed by an EpMotion 5070 Liquid Handling Robot (Eppendorf, Germany) to improve data reproducibility. PCR efficiency (between 90-100\%) and reactions specificity were verified by melting curve analysis (ramping rates of $0.5^{\circ} \mathrm{C} / 10 \mathrm{~s}$ over a temperature range of $55-95^{\circ} \mathrm{C}$ ) and linearity of serial dilutions of RT reactions. Each sample was tested in triplicate and the fluorescence data acquired during the extension phase was normalized by the delta- delta $\mathrm{Ct}$ method $^{38}$ using $\beta$-actin as the housekeeping gene.

Statistical analysis. Statistical analyses were performed after all data was checked for normality (Shapiro-Wilk test) and homogeneity of variances (Levene's test). The analysis of variance was performed applying two-way ANOVA test, with diet (CTRL and GRA) and infection (Phdp) as independent factors. Significant differences were considered for $\mathrm{p}<0.05$. The statistic software package used was SigmaPlot 12 (Systat Software Inc., U.S.A.) and information regarding experimental unit and $\mathrm{N}$ is presented in Supplementary Fig. 1 (Fig. S1). Multivariate analysis (Partial Least Squares-Discriminant Analysis; PLS-DA) was also performed to find discriminative features among groups by means of the EZ-Info software (Umetrics, Sweden). The contribution of genes in the PCR-arrays to the PLS-DA models was assessed by means of variable importance in projection (VIP) measurements. A VIP score $>1$ was considered an adequate threshold to determine discriminant variables in the PLS-DA model ${ }^{39,40}$. 


\begin{tabular}{|l|l|l|l|l|l|l|l|l|l|l|l|l|}
\hline Days Post-Infection & \multicolumn{10}{|l|}{} \\
\hline DIET_INFECTION & $\mathbf{1}$ & $\mathbf{2}$ & $\mathbf{3}$ & $\mathbf{4}$ & $\mathbf{5}$ & $\mathbf{6}$ & $\mathbf{7}$ & $\mathbf{8}$ & $\mathbf{9}$ & $\mathbf{1 0}$ & $\begin{array}{l}\text { Total } \\
\text { Dead }\end{array}$ & \% survival \\
\hline CTRL_PLACEBO & 0 & 0 & 0 & 0 & 0 & 0 & 0 & 0 & 0 & 0 & 0 & $100.00^{\mathrm{a}}$ \\
\hline CTRL_PLACEBO & 0 & 0 & 0 & 0 & 0 & 0 & 0 & 0 & 0 & 0 & 0 & $100.00^{\mathrm{a}}$ \\
\hline GRA_PLACEBO & 0 & 0 & 0 & 0 & 0 & 0 & 0 & 0 & 0 & 0 & 0 & $100.00^{\mathrm{a}}$ \\
\hline GRA_PLACEBO & 0 & 0 & 0 & 0 & 0 & 0 & 0 & 0 & 0 & 0 & 0 & $100.00^{\mathrm{a}}$ \\
\hline CTRL_PHDP & 0 & 0 & 2 & 0 & 1 & 2 & 1 & 0 & 0 & 0 & 6 & $80.00^{\mathrm{b}}$ \\
\hline CTRL_PHDP & 1 & 0 & 1 & 2 & 1 & 0 & 2 & 0 & 0 & 0 & 7 & $76.67^{\mathrm{b}}$ \\
\hline GRA_PHDP & 0 & 0 & 0 & 2 & 0 & 0 & 4 & 0 & 0 & 0 & 6 & $80.00^{\mathrm{b}}$ \\
\hline GRA_PHDP & 0 & 0 & 2 & 0 & 0 & 0 & 0 & 0 & 0 & 0 & 2 & $93.10^{\mathrm{b}}$ \\
\hline
\end{tabular}

Table 1. Mortality and survival percentage recorded for 10 days post-infection in seabass fed the experimental diets (CTRL or GRA) and subjected to Phdp infection. $\mathrm{N}=2$ tanks per group. Superscript letters indicate significant differences between infected and placebo groups $(\mathrm{p}<0.05)$.

\section{Results}

Fish performance and mortality. Seabass showed no differences between dietary groups for initial and final body weight, as well as for feed intake calculated at day 90 (Supplementary Table S2). After infection fish were monitored daily and all mortalities recorded (Table 1). Placebo fish from both GRA and CTRL diets presented $100 \%$ survival rates. Regarding fish infected with Phdp, the first mortalities occurred in the CTRL diet, specifically at day 1 and day 3 post-infection. At day 3, mortalities were observed in both dietary groups infected with Phdp. Overall, deaths occurred within the predicted time-line for bacterial infections, i.e. between days 3 and 7 post inoculation.

Plasma bioindicators. The evaluation of glucose levels (Fig. 1a) revealed no differences between diets, infection or the interaction between both factors. On the contrary, triglycerides levels (Fig. 1b) within placebo groups ( $\mathrm{p}=0.018$ ), showed lower triglycerides levels in seabass fed GRA compared to CTRL and no differences were detected between diets within Phdp infected fish. In addition, within each diet, highly significant decreases were detected in Phdp infected fish when compared with placebo $(\mathrm{p}<0.001)$. No statistical significance was found for the interaction between diet and infection

Immune parameters in plasma. The measurement of circulating peroxidase activity levels (Fig. 2a) revealed differences between dietary treatments $(\mathrm{p}<0.05)$ and an interaction between diet and infection $(\mathrm{p}<0.05)$. Specifically, fish fed GRA diet presented lower peroxidase levels in both placebo and Phdp groups when compared with these fed the CTRL diet. Lysozyme activity (Fig. 2b) showed statistical differences between dietary groups with higher levels observed for GRA diet $(\mathrm{p}<0.001)$ and lower levels in Phdp groups when compared with placebo $(\mathrm{p}=0.004)$. Additionally, the interaction of both factors (diet and infection) evidenced that seabass fed the CTRL diet had lower lysozyme activity $(\mathrm{p}=0.005)$ than fish fed GRA diet.

Antioxidant parameters in liver. Lipid peroxidation (Fig. 3a) displayed significant differences between diets within the Phdp infected groups, with lower peroxidation in seabass fed GRA diet $(\mathrm{p}=0.018)$. Considering the CTRL diet alone, seabass infected with Phdp revealed higher lipid peroxidation $(p=0.002)$. Catalase activity (Fig. 3b) was higher in fish fed GRA diet within the placebo groups $(\mathrm{p}=0.002)$, and no statistical differences were detected between diets in Phdp infected groups or the interaction of both diet and infection. Glutathione $\mathrm{s}$-transferase activity (Fig. $3 \mathrm{c})$ significantly increased $(\mathrm{p}<0.001)$ in fish fed GRA diet in both placebo and Phdp groups.

Gene expression analysis. The effects of diet and infection were assessed using specific PCR-arrays focused on genes related to cell redox homeostasis and response to oxidative stress in liver, or immune response and cell proliferation in head kidney and spleen. The expression results for each experimental group and tissue, and the corresponding two-way ANOVA analysis can be found in Supplemental Tables S6-S8. The effect of diet was more evident in liver and head kidney comparatively to the effect of the Phdp infection. In the liver, the expression of 13 out of 19 genes was found to be differentially modulated by diet, whereas only 6 genes were differentially expressed due to infection, and 7 genes by the combination of both factors. In head kidney, diet led to the differential expression of 9 out of 29 genes, while 4 genes were affected by the infection, and the combination of diet and infection contributed to the differential expression of 7 genes. The relative effect of diet was less evident in the spleen, as the same number of genes, 7 , was differentially expressed by diet or infection, whereas their combination affected 3 genes.

A multivariate analysis approach was used to visualize the interplay between diet and infection. For instance, in liver, $77 \%$ of total variance was explained by 4 components, with the 3 main components defining more than $67 \%$ of variance (Fig. 4a). Seabass fed CTRL and GRA diets were clearly separated within the first component (26.10\% of total variance), whereas separation along component 2 (18.87\% of total variance, Fig. $4 \mathrm{~b})$ and component 3 (22.23\% of total variance, Fig. 4c) contributed to the differentiation of infected and non-infected fish within each dietary group. This approach also revealed which genes presented a higher contribution to variation (VIP $\geq 1$, Fig. 4d). The main contributors to component 1 , which reflected the effect of diet were genes encoding 
Glucose

a

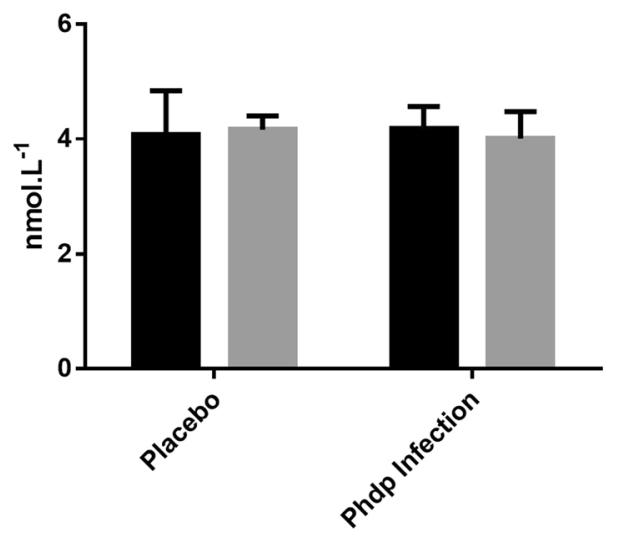

Triglycerides

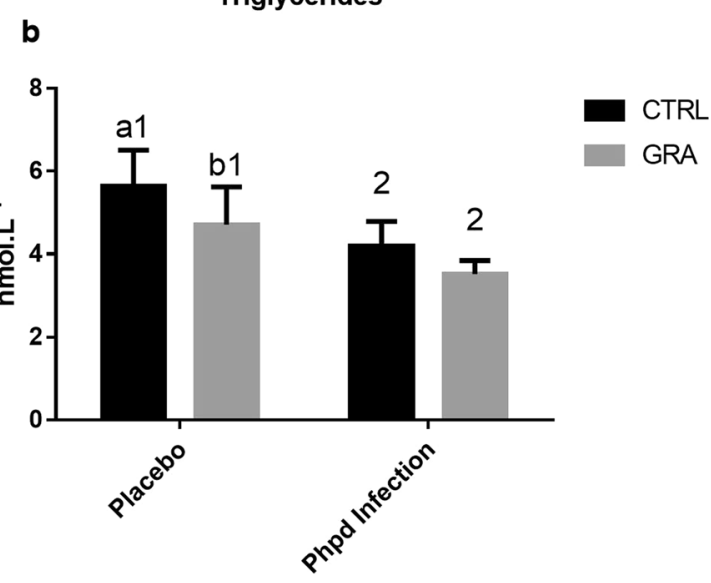

Figure 1. Glucose (a) and Triglycerides (b) levels analysed in plasma of seabass fed the experimental diets (CTRL or GRA) and subjected to Phdp infection. Results presented as mean \pm standard deviation. $\mathrm{N}=16$ fish per group. Different letters indicate significant differences between diets and different numbers indicate differences between infection and placebo $(\mathrm{p}<0.05)$.

heat shock proteins ( $g r p-78, \operatorname{grp}-170, \operatorname{grp}-94, \operatorname{grp}$-75) that were found to be down-regulation in seabass fed GRA diet, together with $\operatorname{prdx1}$, sirt5, gr and sirt1. VIP contribution of 2 components highlighted that the differential response to Phdp infection was mainly due to the down-regulation of prdx4 and mn-sod. Separation along component 3 revealed the contribution of $c s, p r d x 5$ and $g p x 4$, and for the 2 later genes no significant effect of diet or infection was found, but a significant interaction of both factors was evidenced.

PLS-DA analysis of transcriptional response along component 1 in head kidney also highlighted a clear separation regarding diets ( $40.82 \%$ of total variance) (Fig. $5 \mathrm{~b})$. Scores of components 1 and 2 allowed to discriminate between infected and non-infected individuals fed the CTRL diet (Fig. 5c), although this separation was better accomplished along component 3, which explains $23.05 \%$ of total variance (Fig. $5 \mathrm{~d}$ ). In seabass fed the GRA diet, infected and non-infected individuals overlapped in all scores and were therefore analysed together. With this approach, the three components explained $78 \%$ of total variance (Fig. 5a). The most relevant VIP in component 1 for fish fed GRA diet revealed the contribution of several genes in group separation via up-regulation (il34, ccr 9 , $c d 33$ ) or down-regulation ( $m i f, i l 1 b$, defb, $a 2 m, m y d 88$ ). VIP analysis after two components highlighted the role of $g 8 \times 1$ and $m m d$, which were down-regulated with infection in individuals fed CTRL diet. This separation was more evident with component 3, in which a clear up-regulation of IgMs was evident in infected fish of both dietary groups. The down-regulation of leap 2 caused by Phdp infection was also highlighted as a relevant contributor for VIP after 3 components, regardless of the low expression level of this gene in head kidney.

Regarding spleen, PLS-DA analysis only discriminated two components, with low supported (30\%) or predicted $(11 \%)$ variance and with no clear separation among experimental groups in the scores plot (Supplemental Fig. S2).

\section{Discussion}

Dietary supplementation has emerged as an indispensable tool to improve fish health either by boosting immunity, using specific molecules such as $\beta$-glucans, or by providing readily available antioxidants such as vitamins. In the present work we evaluated the contribution of dietary $5 \%$ Gracilaria sp. aqueous extract supplementation in seabass immune and antioxidant capacities when infected with Phdp.

In the present work seabass weight and feed intake showed no differences between diets supporting the use of Gracilaria sp. at 5\% supplementation level. These results were calculated at the end of the experiment since weighing procedures would act as an abiotic stressor compromising the results of the bacterial infection ${ }^{41}$. Nevertheless, the absence of differences in FBW and VFI between fish fed the CTRL and GRA diets is in accordance with previous tests conducted in seabass using the inclusion of two different Gracilaria species (G. bursa-pastoris and G. cornea) at 5 and $10 \%$ levels, in which no negative consequences on growth performance, nutrient utilisation and body composition were detected ${ }^{22}$. Furthermore, within placebo groups, GRA diet significantly lowered triglycerides levels, suggesting that Gracilaria sp. supplementation modulates seabass fatty acid metabolism pathways. However, Phdp overrode the effect of diet, consequently no differences were observed in glucose and triglycerides levels after infection. The results obtained in placebo groups substantiate the antihyperlipidemic effect described in rats ${ }^{42}$, mice ${ }^{43}$, chickens ${ }^{44}$ and zebrafish ${ }^{43}$ when fed diets supplemented with seaweeds, as well as the lower cholesterol and triglyceride levels observed in Japanese flounder (Paralichthys olivaceus) fed diets supplemented with Eucheuma denticulatum ${ }^{45}$ and barramundi (Lates calcarifer) fed diets containing Gracilaria pulvinate ${ }^{46}$.

Regarding mortality, our results validate the use of Gracilaria sp. supplementation as an effective tool to delay photobacteriosis since groups fed the CTRL diet registered the earliest deaths. Additionally, despite no significant differences in cumulative mortality, the total number of dead fish was lower in GRA group. Similar results have been found by Van Doan, et al. ${ }^{47}$ when feeding basa fish (Pangasius bocourti) with diets supplemented with agar. 
Peroxidase

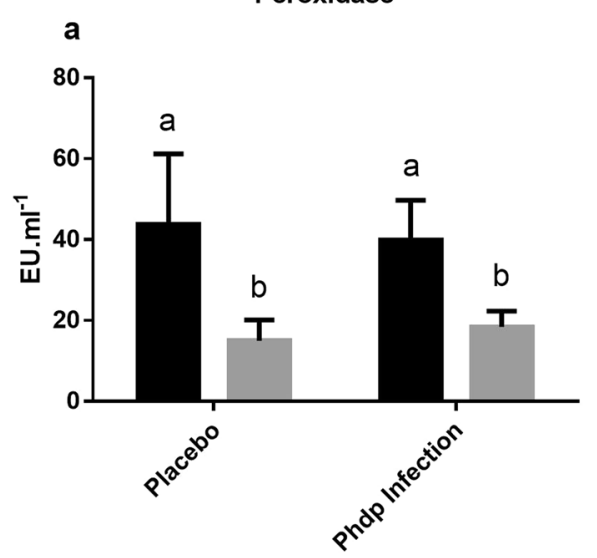

Lyzozyme

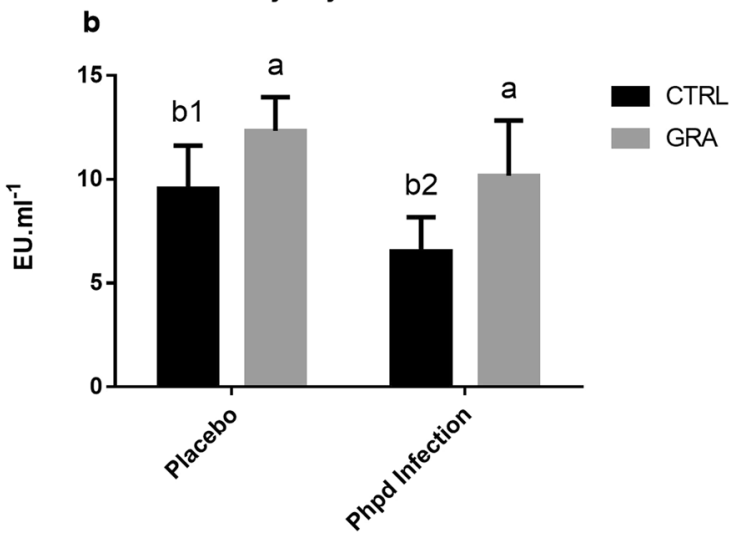

Figure 2. Peroxidase (a) and lysozyme (b) activities determined in plasma of seabass fed the experimental diets (CTRL or GRA) and subjected to Phdp infection. Results presented as mean \pm standard deviation. $\mathrm{N}=16$ fish per group. Different letters indicate significant differences between diets and different numbers indicate differences between infection and placebo $(\mathrm{p}<0.05)$.
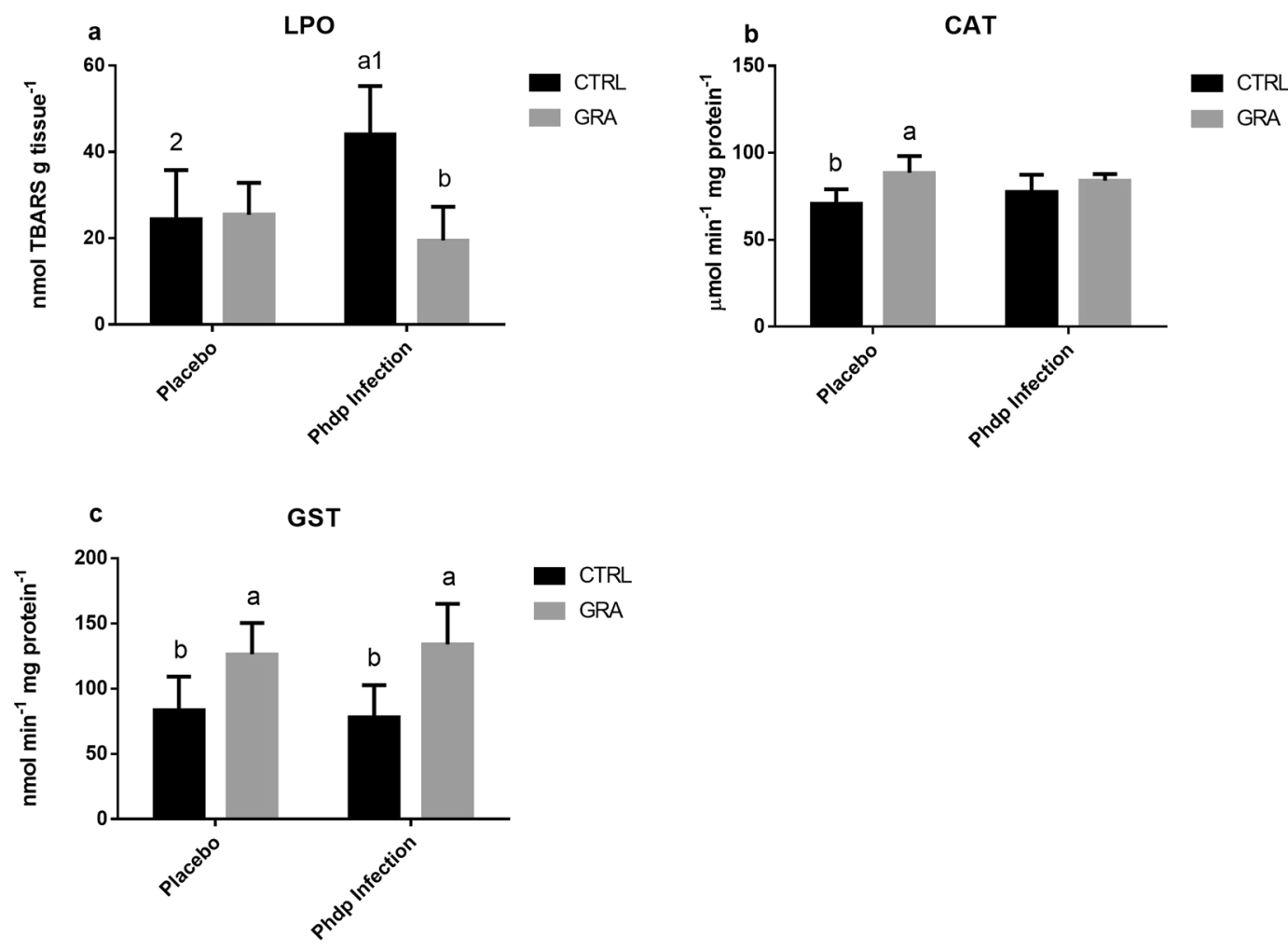

Figure 3. Lipid peroxidation (a), Catalase (b) and glutathione s-transferase (c) activities determined in liver of seabass fed the experimental diets (CTRL or GRA) and subjected to Phdp infection. Results presented as mean \pm standard deviation. $\mathrm{N}=16$ fish per group. Different letters indicate significant differences between diets and different numbers indicate differences between infection and placebo $(\mathrm{p}<0.05)$.

Also, improved resistance to vibriosis was described by Castro, et al ${ }^{48}$ when treating turbot (Scophthalmus maximus) phagocytes with seaweed water-soluble extracts.

The current work also intended to evaluate the mechanisms through which Gracilaria sp. supplementation nutritionally-modulated fish resistance to infection, by accessing the innate immune indicators lysozyme and peroxidase. Both indicators were selected since macrophages engage immediately after infection in defence mechanisms releasing the peroxidases stored in their cytoplasmic granules ${ }^{49}$, causing an initial increase in plasmatic levels that progressively decreases over time ${ }^{50}$. The current study showed that peroxidase levels decreased in both infected and placebo groups fed GRA diet, leading to the hypothesis that GRA may elicit an immediate 
a

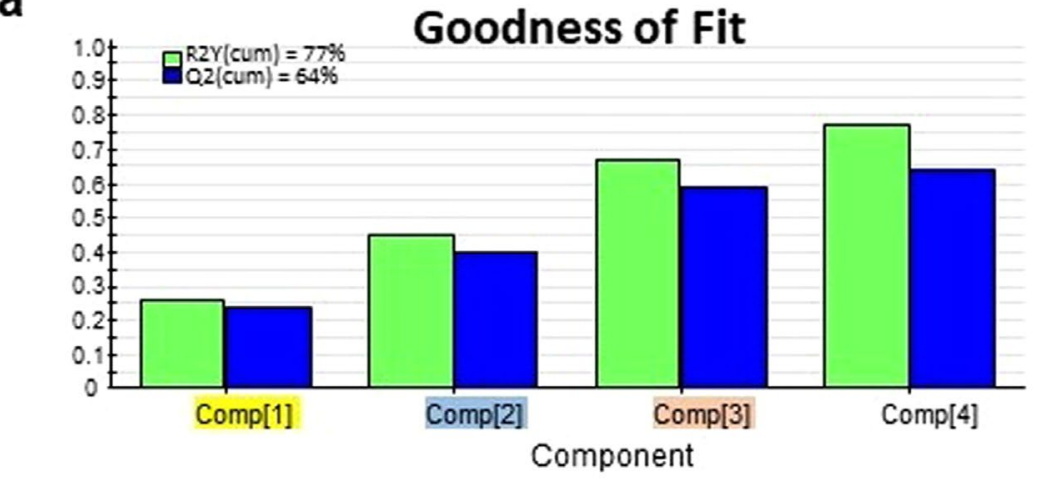

d

\begin{tabular}{ll}
\multicolumn{2}{c}{ VIP[1] 21} \\
grp-78 & 1.57 \\
grp-170 & 1.49 \\
grp-94 & 1.36 \\
prdx1 & 1.31 \\
sirt5 & 1.30 \\
grp-75 & 1.25 \\
gr & 1.15 \\
sirt1 & 1.12
\end{tabular}

b

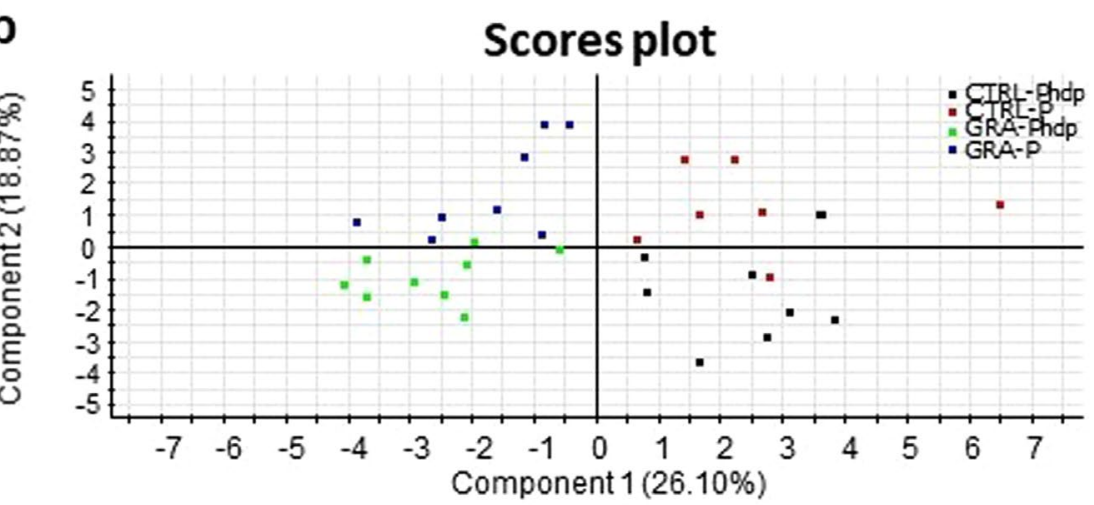

VIP $[2] \geq 1$

\begin{tabular}{l|l}
\hline prdx4 & 1.39 \\
\hline mn-5od & 1.29 \\
\hline grp-78 & 1.25 \\
grp-170 & 1.22 \\
sirt1 & 1.20 \\
grp-94 & 1.09 \\
sirt5 & 1.09 \\
prdx1 & 1.07 \\
ucp1 & 1.00
\end{tabular}

C

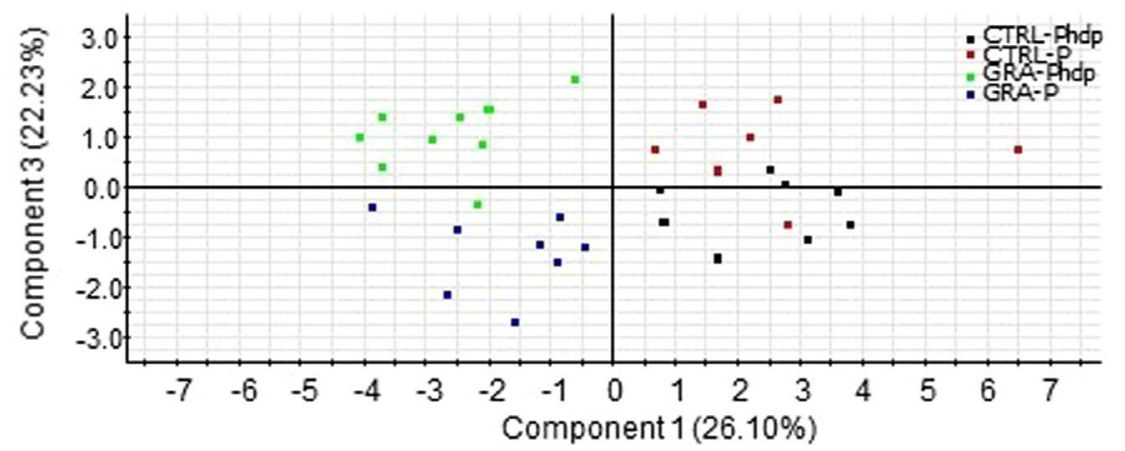

VIP[3] $\geq 1$

\begin{tabular}{|l|l|}
\hline cs & 1.32 \\
\hline sirt1 & 1.20 \\
\hline prdx5 & 1.18 \\
\hline prdx4 & 1.14 \\
\hline mn-sod & 1.08 \\
\hline grp-170 & 1.07 \\
\hline grp-94 & 1.07 \\
\hline grp-78 & 1.05 \\
\hline gpx4 & 1.04 \\
\hline prdx1 & 1.04 \\
\hline gpx1 & 1.00 \\
\hline
\end{tabular}

Figure 4. Discriminant analysis (PLS-DA) of liver molecular signatures of seabass altered by dietary Gracilaria sp. supplementation and/or Phdp infection ( $\mathrm{N}=20$ fish per group). (a) Cumulative coefficients of goodness of fit (R2, white bars) and prediction (Q2, grey bars) by each component; 77\% of total variance is explained by four components. (b) PLS-DA score plot of acquired data from infected individuals along component 1 and 2. (c) PLS-DA score plot of acquired data from infected individuals along component 1 and 3. (d) Ordered list of markers by variable importance (VIP) in the projection of PLS-DA model for group differentiation. Markers with VIP values $>1$ after the first, second and third components are highlighted in yellow, blue and orange, respectively.

response, which was no longer detectable 10 days post infection. Leukocytes also respond to bacterial infection by releasing lysozyme, an enzyme with lytic activity against pathogens ${ }^{49}$ and is overexpressed in the presence of microbial agents or after immunization procedures ${ }^{51}$. In the current study, lysozyme activity increased in seabass fed GRA diet compared with fish fed CTRL, suggesting a boosting effect possibly triggered by polysaccharides present in the seaweed-supplemented diet. Considering the current results, it is plausible to infer that dietary Gracilaria sp. modulates seabass immune system, eliciting a primary response, which may be advantageous to delay photobacteriosis.

In infectious milieus, activated phagocytes increase ROS production whose microbicidal properties are important to degrade pathogens ${ }^{48}$. However excessive ROS production can lead to oxidative stress, a phenomena previously described in infection scenarios ${ }^{52}$. In the current study, dietary Gracilaria sp. may play a role maintaining the redox balance after infection, as lower lipid peroxidation values were detected in infected fish 
a

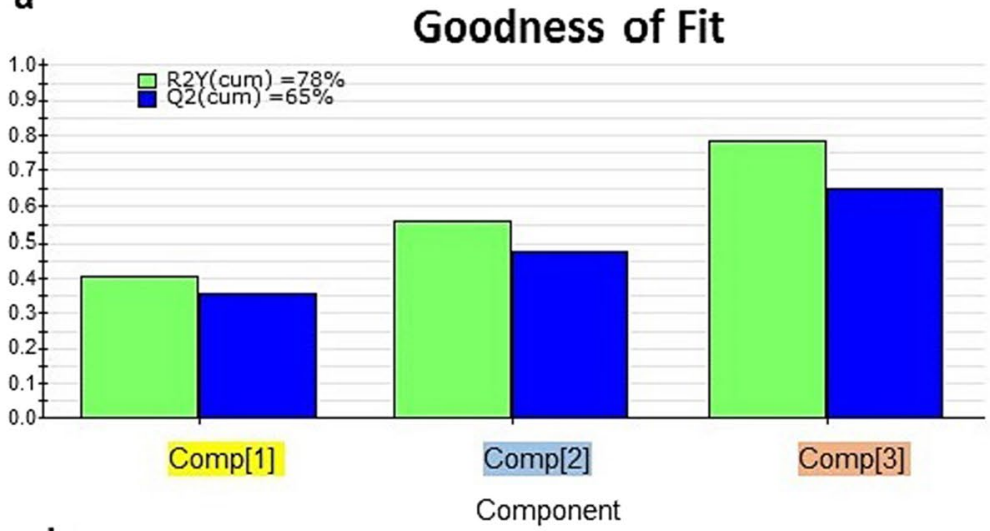

b

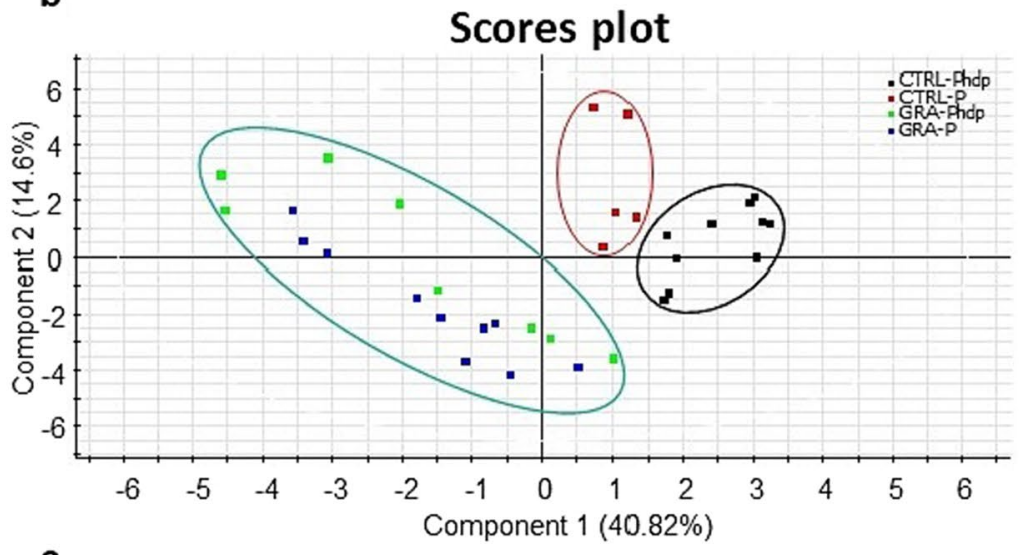

C

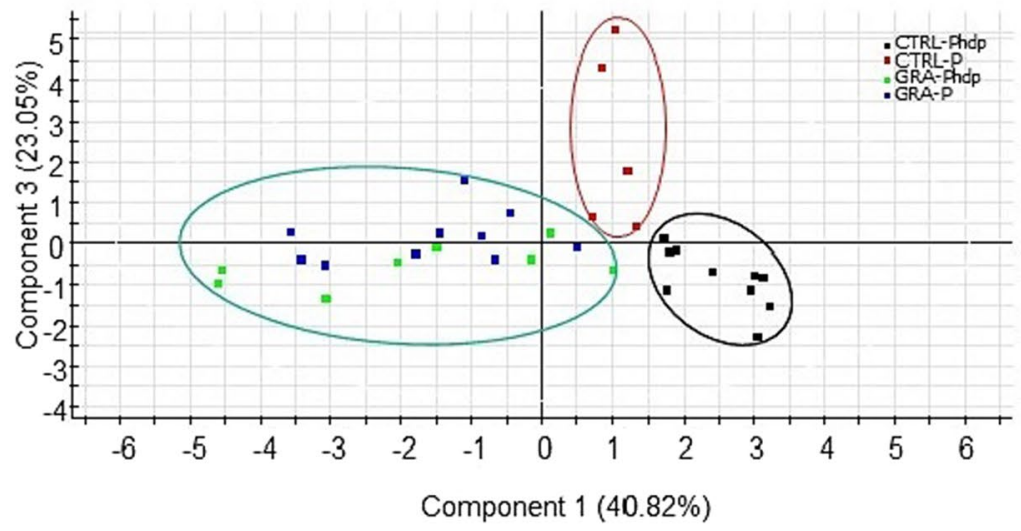

d

\begin{tabular}{|c|c|}
\hline \multicolumn{2}{|c|}{$\operatorname{VIP}[1] \geq 1$} \\
\hline il34 & 2.1 \\
\hline mif & 1. \\
\hline illb & 1. \\
\hline ackr4 & 1 \\
\hline igmb & 1. \\
\hline $\mathrm{Ccr} 9$ & 1. \\
\hline$c d 33$ & 1. \\
\hline$d e f b$ & 1. \\
\hline & \\
\hline & \\
\hline
\end{tabular}

VIP $[2] \geq 1$

\begin{tabular}{|l|l|}
\hline mif & 1.81 \\
\hline il34 & 1.80 \\
\hline$a c k r 4$ & 1.31 \\
\hline il1b & 1.30 \\
\hline defb & 1.17 \\
\hline g8x1 & 1.17 \\
\hline$c c r 9$ & 1.16 \\
\hline igmb & 1.15 \\
\hline$c d 33$ & 1.10 \\
\hline mmd & 1.07 \\
\hline$a 2 m$ & 1.04 \\
\hline myd88 & 1.01 \\
\hline
\end{tabular}

VIP $[3] \geq 1$

\begin{tabular}{l|l|} 
il34 & 1.55 \\
mif & 1.53
\end{tabular}

il1 $b \quad 1.34$

cd33 1.23

\begin{tabular}{|l|l|l|}
\hline g8x1 & 1.20 \\
\hline
\end{tabular}

myd88 1.16

igms 1.16

ackr4 1.11

\begin{tabular}{l|l} 
crp & 1.10 \\
\hline
\end{tabular}

\begin{tabular}{l|l} 
csf1r & 1.08 \\
\hline
\end{tabular}

igmb $\quad 1.06$

ccrs 1.03

leap2 1.03

defb 1.01

Figure 5. Discriminant analysis (PLS-DA) of head kidney molecular signatures of seabass altered by dietary Gracilaria sp. supplementation and/or Phdp infection ( $\mathrm{N}=20$ fish per group). (a) Cumulative coefficients of goodness of fit (R2, white bars) and prediction (Q2, grey bars) by each component; $78 \%$ of total variance is explained by four components. (b) PLS-DA score plot of acquired data from infected individuals along component 1 and 2. (c) PLS-DA score plot of acquired data from infected individuals along component 1 and 3. (d) Ordered list of markers by variable importance (VIP) in the projection of PLS-DA model for group differentiation. Markers with VIP values $>1$ after the first, second and third components are highlighted in yellow, blue and orange, respectively.

fed GRA when compared to these fish fed the CTRL diet. Our results are in line with the decrease in lipid peroxidation products observed in rainbow trout (Oncorhynchus mykiss) when fed diets supplemented with Gracilaria pygmaea ${ }^{53}$. Further indication of an upregulated detoxifying activity in seabass fed GRA diet was provided by glutathione S-transferase (GST) analysis, as GST activity was increased in both infected and placebo groups fed that diet. Recently Thanigaivel, et al. ${ }^{54}$ have shown that the antioxidant response of Oreochromis mossambicus to a bacterial infection with Aeromonas is improved in fish fed microencapsulated extracts of Gracilaria foliifera and Sargassum longifolium. 
The reported changes in plasma bioindicators and enzyme activities in response to GRA supplementation and/or bacterial infection pointed towards differential expression signatures in fish facing these challenges. Indeed, in the liver of seabass fed GRA diet, a clear decrease was detected in the expression of genes encoding heat shock proteins and molecular chaperones i.e. grp 94 , grp 170, grp 78, grp 75 and $m$ thsp 10 , established markers of fish response to stressors $\mathrm{s}^{55}$. Besides their involvement in stress responses, heat shock proteins are also involved in immunity processes ${ }^{56,57}$ playing a major role mediating the development of inflammation through specific and non-specific responses to infections ${ }^{58}$. Gracilaria sp. supplementation also affected the hepatic expression of antioxidant enzymes, either inducing a down-regulation (glutathione reductase, $g r$; peroxiredoxin 1, $\operatorname{prd} \times 1$ ) or a reverse response to bacterial infection (glutathione peroxidase $4, g p x 4$; peroxiredoxin 5 , prd $x 5$ ) in comparison to CTRL. Considering their function in cell defence mechanisms as modulators of inflammation and cell protection $^{59,60}$, the down-regulated expression suggests a protective role of Gracilaria sp. in seabass response to pathogens. Moreover, fish sirtuins ( sirt) were already demonstrated to respond to dietary changes ${ }^{61}$ and in our results sirt 1 and 5 hepatic expression levels showed an inverse pattern between dietary groups infected with Phdp. These results seem to follow the same mechanistic regulation as in mammals, where sirt1 inhibition is associated to sirt5 overexpression and are linked with the resolution of inflammation ${ }^{62}$. Globally, genes encoding for antioxidant enzymes and redox homeostasis were down-regulated in the liver of seabass fed GRA diet, suggesting a direct contribution of Gracilaria sp. to the antioxidant processes, dismantling the need for increased transcription.

Head-kidney gene expression analysis also revealed that GRA diet modulated the expression of cytokines, key regulators of infection ${ }^{63}$, especially when infected with Phdp. Palstra, et al. ${ }^{64}$ also found improved chemotaxis and chemokine-mediated signalling in the defence against Gram-positive bacterium in Salmo salar fed diets supplemented with Laminaria digitata. In our work, seabass fed GRA diet showed a decreased expression of the pro-inflammatory cytokine $i l-1 \beta$ at $10 \mathrm{dpi}$, and since this cytokine acts as a chemoattractant for leucocytes, which involves the recruitment of other interleukins ${ }^{65}$, its decreased transcription may represent the resolution of inflammation. In line with this assessment, IL-1 $\beta$ was reported to enhance macrophage functions in seabass infected with Vibrium anguillarum immediately after infection ${ }^{66}$ and to decrease expression in rainbow trout (Oncorhynchus mykiss) head kidney 8 days after exposure to Aeromonas salmonicida ${ }^{67}$. Likewise, in our work the anti-inflammatory cytokines $i l-10$ and $i l-20$ increased in seabass fed GRA and infected with Phdp. IL-20 in fish has been identified as belonging to the IL-10 family, and both these cytokines were previously observed to increase in fish macrophages after infection with Yersinia ruckeri ${ }^{68}$. Additionally, the transcription levels of $i l-34$ together with $c s f 1 r$, and $c d 33$ increased in infected seabass fed GRA diet, suggesting higher involvement of macrophages in defence against Phdp.

The influence of dietary Gracilaria sp. supplementation in seabass is further evidenced by the up-regulation of the lymphokine mif, the chemokine receptor $a c k r 4$ and the antimicrobial peptide $d e f b$ in response to infection, all involved in immunosuppression ${ }^{65}$. Immunoglobulins (Ig) which are involved in both innate and adaptive immunity showed increased expression in infected fish fed GRA diet. IgM has been described to activate complement and lysozyme triggering the lysis and opsonisation of pathogens ${ }^{69,70}$, and also mediate agglutination, phagocytosis and pathogen removal ${ }^{71}$. Therefore, the observed up-regulation of igm together with the increased lysozyme activity, further supports the hypothesis that dietary Gracilaria sp. supplementation positively regulates seabass resistance to Phdp. Overall, the up-regulated expression in immune related genes observed in seabass fed GRA diet when compared to CTRL suggests heightened immunity against infection with Phdp.

To summarize, our results show that a dietary supplementation of $5 \%$ aqueous extract of Gracilaria sp. is feasible for seabass without compromising weight gain or affecting feed consumption rates. Moreover, when infected with $P$. damselae, seabass fed GRA diet were more resistant to the pathogen, constituting an advantageous feature in aquaculture industry. Additionally, lysozyme and peroxidase in seabass fed GRA revealed increased resistance to pathogen proliferation. The protective role of Gracilaria sp. in oxidation processes resulted in lower LPO levels and increased GST activity, suggesting amplified capacity to respond to higher ROS levels produced during inflammation. Seabass fed GRA diet also evidenced differential expression of key genes involved in the immune and antioxidant systems when compared to the CTRL. More specifically, a shift in the contribution of determinant genes for the inflammatory process was observed in GRA groups evidencing a determinant role of Gracilaria sp. supplementation in the up-regulation of immune and antioxidant related pathways.

Ethical statement. All procedures were conducted under the supervision of an accredited expert in laboratory animal science by the Portuguese Veterinary Authority (1005/92, DGV-Portugal, following FELASA category $\mathrm{C}$ recommendations), according to the guidelines on the protection of animals used for scientific purposes from the European directive 2010/63/UE. The experiment took place at the Abel Salazar Biomedical Sciences Institute (ICBAS), University of Porto (Portugal). This study was approved by the ORBEA (Organismo Responsável pelo Bem-Estar dos Animais), the Institutional Animal Care and Use Committee (IACUC) of ICBAS.

\section{Data availability}

The datasets generated during the current study are available on request to the corresponding author.

Received: 9 November 2018; Accepted: 2 October 2019;

Published online: 06 November 2019

\section{References}

1. Conte, F. S. Stress and the welfare of cultured fish. Applied Animal Behaviour Science 86, 205-223, https://doi.org/10.1016/j. applanim.2004.02.003 (2004).

2. Douxfils, J. et al. Dietary $\beta$-glucans differentially modulate immune and stress-related gene expression in lymphoid organs from healthy and Aeromonas hydrophila-infected rainbow trout (Oncorhynchus mykiss). Fish \& Shellfish Immunology 63, 285-296, https:// doi.org/10.1016/j.fsi.2017.02.027 (2017) 
3. Soares, F., Fernández Monzón, I., Costas, B. \& Gavaia, P. Non-infectious disorders of warmwater fish (2014).

4. Carraro, R. et al. Development of a real-time PCR assay for rapid detection and quantification of Photobacterium damselae subsp. piscicida in fish tissues. Journal of Fish Diseases 41, 247-254, https://doi.org/10.1111/jfd.12703 (2018).

5. Miest, J. J. et al. The influence of dietary $\beta$-glucan, PAMP exposure and Aeromonas salmonicida on apoptosis modulation in common carp (Cyprinus carpio). Fish \& Shellfish Immunology 33, 846-856, https://doi.org/10.1016/j.fsi.2012.07.014 (2012).

6. Labh, S. N. \& Shakya, S. R. Application of immunostimulants as an alternative to vaccines for health management in aquaculture. International Journal of Fisheries and Aquatic Studies 2, 153-156 (2014).

7. Gannam, A. L. \& Schrock, R. M. Immunostimulants in fish diets. Journal of Applied Aquaculture 9, 53-89, https://doi.org/10.1300/ J028v09n04_06 (1999).

8. Serra, C. R. et al. Selection of carbohydrate-active probiotics from the gut of carnivorous fish fed plant-based diets. Scientific reports 9, 6384 (2019).

9. Turchini, G. M., Ng, W.-K. \& Tocher, D. R. (eds Giovanni M. Turchini, Wing-Keong Ng, \& Douglas Redford Tocher) (Taylor \& Francis, Boca Raton:, 2010).

10. Cian, R. E., Drago, S. R., de Medina, F. S. \& Martínez-Augustin, O. Proteins and carbohydrates from red seaweeds: evidence for beneficial effects on gut function and microbiota. Marine drugs 13, 5358-5383, https://doi.org/10.3390/md13085358 (2015).

11. Chojnacka, K., Saeid, A., Witkowska, Z. \& Tuhy, L. Biologically Active Compounds in Seaweed Extracts -the Prospects for the Application. Vol. 3 (2012).

12. Hutkins, R. W. et al. Prebiotics: why definitions matter. Curr Opin Biotechnol 37, 1-7, https://doi.org/10.1016/j.copbio.2015.09.001 (2016).

13. Bonfim-Mendonça, Pd. S., Capoci, I. R. G., Tobaldini-Valerio, F. K., Negri, M. \& Svidzinski, T. I. E. Overview of b-Glucans from Laminaria spp.: Immunomodulation Properties and Applications on Biologic Models. International Journal of Molecular Sciences 18, 1629, https://doi.org/10.3390/ijms18091629 (2017).

14. Cho, S. H. et al. The antioxidant properties of brown seaweed (Sargassum siliquastrum) extracts. Journal of medicinal food 10, 479-485, https://doi.org/10.1089/jmf.2006.099 (2007).

15. Gerwick, W. et al. Eicosanoids from the Rhodophyta: New metabolism in the algae. Vol. 204-205 (1990).

16. Ricciotti, E. \& FitzGerald, G. A. Prostaglandins and inflammation. Arteriosclerosis, thrombosis, and vascular biology 31, 986-1000, https://doi.org/10.1161/ATVBAHA.110.207449 (2011).

17. Esser-von Bieren, J. In Biological Chemistry Vol. 3981177 (2017).

18. Montero, D. et al. Replacement of dietary fish oil by vegetable oils affects humoral immunity and expression of pro-inflammatory cytokines genes in gilthead sea bream Sparus aurata. Fish \& Shellfish Immunology 29, 1073-1081, https://doi.org/10.1016/j. fsi.2010.08.024 (2010)

19. Calduch-Giner, J. A. et al. Dietary vegetable oils do not alter the intestine transcriptome of gilthead sea bream (Sparus aurata), but modulate the transcriptomic response to infection with Enteromyxum leei. BMC Genomics 13, 470, https://doi.org/10.1186/14712164-13-470 (2012)

20. Estensoro, I., Calduch-Giner, J. A., Kaushik, S., Perez-Sanchez, J. \& Sitja-Bobadilla, A. Modulation of the IgM gene expression and IgM immunoreactive cell distribution by the nutritional background in gilthead sea bream (Sparus aurata) challenged with Enteromyxum leei (Myxozoa). Fish \& Shellfish Immunology 33, 401-410, https://doi.org/10.1016/j.fsi.2012.05.029 (2012).

21. Krogdahl, Å., Penn, M., Thorsen, J., Refstie, S. \& Bakke, A. M. Important antinutrients in plant feedstuffs for aquaculture: an update on recent findings regarding responses in salmonids. Aquaculture Research 41,333-344, https://doi. org/10.1111/j.1365-2109.2009.02426.x (2010).

22. Martin, S. A. M. \& Król, E. Nutrigenomics and immune function in fish: new insights from omics technologies. Developmental \& Comparative Immunology 75, 86-98, https://doi.org/10.1016/j.dci.2017.02.024 (2017).

23. Pérez-Sánchez, J. et al. Dietary oils mediate cortisol kinetics and the hepatic mRNA expression profile of stress-responsive genes in gilthead sea bream (Sparus aurata) exposed to crowding stress. Implications on energy homeostasis and stress susceptibility. Comparative Biochemistry and Physiology Part D: Genomics and Proteomics 8, 123-130 (2013).

24. Hoseinifar, S. H. et al. Mucosal immune parameters, immune and antioxidant defence related genes expression and growth performance of zebrafish (Danio rerio) fed on Gracilaria gracilis powder. Fish \& Shellfish Immunology 83, 232-237, https://doi. org/10.1016/j.fsi.2018.09.046 (2018).

25. Vallejos-Vidal, E., Reyes-Lopez, F., Teles, M. \& MacKenzie, S. The response of fish to immunostimulant diets. Fish \& Shellfish Immunology 56, 34-69, https://doi.org/10.1016/j.fsi.2016.06.028 (2016).

26. Magnoni, L. J. et al. Dietary supplementation of heat-treated Gracilaria and Ulva seaweeds enhanced acute hypoxia tolerance in gilthead sea bream (Sparus aurata). Biology open 6, 897-908, https://doi.org/10.1242/bio.024299 (2017).

27. Valente, L. et al. Evaluation of three seaweeds Gracilaria bursa-pastoris, Ulva rigida and Gracilaria cornea as dietary ingredients in European sea bass (Dicentrarchus labrax) juveniles. Aquaculture 252, 85-91 (2006).

28. Sotoudeh, E. \& Jafari, M. Effects of dietary supplementation with red seaweed, Gracilaria pygmaea, on growth, carcass composition and hematology of juvenile rainbow trout, Oncorhynchus mykiss. (2017).

29. Abreu, M. H., Pereira, R., Yarish, C., Buschmann, A. H. \& Sousa-Pinto, I. IMTA with Gracilaria vermiculophylla: productivity and nutrient removal performance of the seaweed in a land-based pilot scale system. Aquaculture 312, 77-87 (2011).

30. Reed, L. J. \& Muench, H. A simple method of estimating fifty per cent endpoints. American Journal of Epidemiology 27, 493-497 (1938). 31. Ellis, A. E. Immunity to bacteria in fish. Fish \& Shellfish Immunology 9, 291-308 (1999).

32. Quade, M. J. \& Roth, J. A. A rapid, direct assay to measure degranulation of bovine neutrophil primary granules. Veterinary immunology and immunopathology 58, 239-248 (1997)

33. Ohkawa, H., Ohishi, N. \& Yagi, K. Assay for lipid peroxides in animal tissues by thiobarbituric acid reaction. Analytical Biochemistry 95, 351-358, https://doi.org/10.1016/0003-2697(79)90738-3 (1979).

34. Bradford, M. M. A rapid and sensitive method for the quantitation of microgram quantities of protein utilizing the principle of protein-dye binding. Analytical Biochemistry 72, 248-254, https://doi.org/10.1016/0003-2697(76)90527-3 (1976).

35. Clairborne, A. Catalase activity In: Greenwald, R.A. (Ed.). 283-284 (CRC Handbook of Methods in Oxygen Radical Research. CRC Press, Boca Raton, 1985).

36. Habig, W. H., Pabst, M. J. \& Jakoby, W. B. Glutathione S-transferases. The first enzymatic step in mercapturic acid formation. Journal of Biological Chemistry 249, 7130-7139 (1974).

37. Calduch-Giner, J. A., Sitjà-Bobadilla, A. \& Pérez-Sánchez, J. Gene expression profiling reveals functional specialization along the intestinal tract of a carnivorous teleostean fish (Dicentrarchus labrax). Frontiers in physiology 7, 359-359, https://doi.org/10.3389/ fphys.2016.00359 (2016).

38. Livak, K. J. \& Schmittgen, T. D. Analysis of relative gene expression data using real-time quantitative PCR and the 2(-Delta Delta C(T)) Method. Methods (San Diego, Calif.) 25, 402-408, https://doi.org/10.1006/meth.2001.1262 (2001).

39. Kieffer, D. A. et al. Mice fed a high-fat diet supplemented with resistant starch display marked shifts in the liver metabolome concurrent with altered gut bacteria. J Nutr 146, 2476-2490, https://doi.org/10.3945/jn.116.238931 (2016).

40. Wold, S., Sjöström, M. \& Eriksson, L. PLS-regression: a basic tool of chemometrics. Chemometrics and Intelligent Laboratory Systems 58, 109-130, https://doi.org/10.1016/S0169-7439(01)00155-1 (2001).

41. Barton, B. A. Stress in fishes: a diversity of responses with particular reference to changes in circulating corticosteroids. Integrative and comparative biology 42, 517-525 (2002). 
42. Matanjun, P., Mohamed, S., Muhammad, K. \& Mustapha, N. M. Comparison of cardiovascular protective effects of tropical seaweeds, Kappaphycus alvarezii, Caulerpa lentillifera, and Sargassum polycystum, on high-cholesterol/high-fat diet in rats. Journal of medicinal food 13, 792-800, https://doi.org/10.1089/jmf.2008.1212 (2010).

43. Nakayama, H. et al. Novel anti-obesity properties of palmaria mollis in zebrafish and mouse models. Nutrients 10, 1401, https://doi. org/10.3390/nu10101401 (2018).

44. Ginzberg, A. et al. Chickens fed with biomass of the red microalga Porphyridium sp. have reduced blood cholesterol level and modified fatty acid composition in egg yolk. Journal of Applied Phycology 12, 325-330, https://doi.org/10.1023/a:1008102622276 (2000).

45. Ragaza, J. A. et al. Dietary supplemental effects of red seaweed Eucheuma denticulatum on growth performance, carcass composition and blood chemistry of juvenile Japanese flounder, Paralichthys olivaceus. Aquaculture Research 46, 647-657, https://doi. org/10.1111/are.12211 (2015).

46. Morshedi, V., Nafisi Bahabadi, M., Sotoudeh, E., Azodi, M. \& Hafezieh, M. Nutritional evaluation of Gracilaria pulvinata as partial substitute with fish meal in practical diets of barramundi (Lates calcarifer). Journal of Applied Phycology 30, 619-628, https://doi. org/10.1007/s10811-017-1199-y (2018).

47. Van Doan, H., Doolgindachbaporn, S. \& Suksri, A. Effects of low molecular weight agar and Lactobacillus plantarum on growth performance, immunity, and disease resistance of basa fish (Pangasius bocourti, Sauvage 1880). Fish \& Shellfish Immunology 41, 340-345, https://doi.org/10.1016/j.fsi.2014.09.015 (2014).

48. Castro, R., Zarra, I. \& Lamas, J. Water-soluble seaweed extracts modulate the respiratory burst activity of turbot phagocytes. Aquaculture 229, 67-78, https://doi.org/10.1016/S0044-8486(03)00401-0 (2004).

49. Alvarez-Pellitero, P. Fish immunity and parasite infections: from innate immunity to immunoprophylactic prospects. Veterinary immunology and immunopathology 126, 171-198, https://doi.org/10.1016/j.vetimm.2008.07.013 (2008).

50. Sitjà-Bobadilla, A., Palenzuela, O. \& Alvarez-Pellitero, P. Immune response of turbot, Psetta maxima (L.) (Pisces: Teleostei), to formalin-killed scuticociliates (Ciliophora) and adjuvanted formulations. Fish \& Shellfish Immunology 24, 1-10, https://doi. org/10.1016/j.fsi.2007.06.007 (2008).

51. Alishahi, M. \& Buchmann, K. Temperature-dependent protection against Ichthyophthirius multifiliis following immunisation of rainbow trout using live theronts. Diseases of aquatic organisms 72, 269-273, https://doi.org/10.3354/dao072269 (2006).

52. Marcogliese, D. J., Brambilla, L. G., Gagné, F. \& Gendron, A. D. Joint effects of parasitism and pollution on oxidative stress biomarkers in yellow perch Perca flavescens. Diseases of aquatic organisms 63, 77-84 (2005).

53. Sotoudeh, E. \& Mardani, F. Antioxidant-related parameters, digestive enzyme activity and intestinal morphology in rainbow trout (Oncorhynchus mykiss) fry fed graded levels of red seaweed, Gracilaria pygmaea. Aquaculture Nutrition 24, 777-785, https://doi. org/10.1111/anu.12606 (2018).

54. Thanigaivel, S., Chandrasekaran, N., Mukherjee, A. \& Thomas, J. Protective efficacy of microencapsulated seaweed extracts for preventing Aeromonas infections in Oreochromis mossambicus. Comparative Biochemistry and Physiology Part C: Toxicology \& Pharmacology 218, 36-45, https://doi.org/10.1016/j.cbpc.2018.12.011 (2019).

55. Iwama, G. K., Afonso, L. O., Todgham, A., Ackerman, P. \& Nakano, K. Are hsps suitable for indicating stressed states in fish? The Journal of experimental biology 207, 15-19 (2004).

56. Ackerman, P. A. \& Iwama, G. K. Physiological and cellular stress responses of juvenile rainbow trout to vibriosis. Journal of Aquatic Animal Health 13, 173-180, doi:10.1577/1548-8667(2001)013<0173:PACSRO > 2.0.CO;2 (2001).

57. Forsyth, R. B., Candido, E. P. M., Babich, S. L. \& Iwama, G. K. Stress protein expression in coho salmon with bacterial kidney disease. Journal of Aquatic Animal Health 9, 18-25, doi: 10.1577/1548-8667(1997)009<0018:SPEICS > 2.3.CO;2 (1997)

58. Roberts, R. J., Agius, C., Saliba, C., Bossier, P. \& Sung, Y. Y. Heat shock proteins (chaperones) in fish and shellfish and their potential role in relation to fish health: a review. Journal of Fish Diseases 33, 789-801, https://doi.org/10.1111/j.1365-2761.2010.01183.x (2010).

59. Valero, Y., Martínez-Morcillo, F. J., Esteban, M. Á., Chaves-Pozo, E. \& Cuesta, A. Fish peroxiredoxins and their role in immunity. Biology 4, 860-880, https://doi.org/10.3390/biology4040860 (2015).

60. Hamed, R. R., Maharem, T. M. \& Guinidi, R. A. M. Glutathione and its related enzymes in the nile fish. Fish Physiology and Biochemistry 30, 189-199, https://doi.org/10.1007/s10695-005-3259-5 (2004).

61. Simo-Mirabet, P., Bermejo-Nogales, A., Calduch-Giner, J. A. \& Perez-Sanchez, J. Tissue-specific gene expression and fasting regulation of sirtuin family in gilthead sea bream (Sparus aurata). Journal of comparative physiology. B, Biochemical, systemic, and environmental physiology 187, 153-163, https://doi.org/10.1007/s00360-016-1014-0 (2017).

62. Villalba, J. M. \& Alcain, F. J. Sirtuin activators and inhibitors. BioFactors (Oxford, England) 38, 349-359, https://doi.org/10.1002/ biof.1032 (2012).

63. Dembic, Z. In The Cytokines of the Immune System 1-16 (Academic Press, 2015).

64. Palstra, A. P., Kals, J., Blanco Garcia, A., Dirks, R. P. \& Poelman, M. immunomodulatory effects of dietary seaweeds in LPS challenged atlantic salmon Salmo salar as determined by deep rna sequencing of the head kidney transcriptome. Front Physiol $\mathbf{9}$, 625, https://doi.org/10.3389/fphys.2018.00625 (2018).

65. Zou, J. \& Secombes, C. The function of fish cytokines. Biology 5, 23 (2016).

66. Chistiakov, D. A., Kabanov, F. V., Troepolskaya, O. D. \& Tischenko, M. M. A variant of the interleukin-1 $\beta$ gene in European sea bass, Dicentrarchus labrax L., is associated with increased resistance against Vibrio anguillarum. Journal of Fish Diseases 33, 759-767, https://doi.org/10.1111/j.1365-2761.2010.01182.x (2010).

67. Mulder, I. E., Wadsworth, S. \& Secombes, C. J. Cytokine expression in the intestine of rainbow trout (Oncorhynchus mykiss) during infection with Aeromonas salmonicida. Fish \& Shellfish Immunology 23, 747-759, https://doi.org/10.1016/j.fsi.2007.02.002 (2007).

68. Reyes-Cerpa, S. et al. In New Advances and Contributions to Fish Biology (InTech, 2012).

69. Boshra, H., Gelman, A. E. \& Sunyer, J. O. Structural and functional characterization of complement C4 and C1s-like molecules in teleost fish: Insights into the evolution of classical and alternative pathways. The Journal of Immunology 173, 349-359, https://doi. org/10.4049/jimmunol.173.1.349 (2004).

70. Uribe, C., Folch, H., Enriquez, R. \& Moran, G. Innate and adaptive immunity in teleost fish: a review. Veterinarni Medicina 56, 486-503 (2011)

71. Mashoof, S. \& Criscitiello, M. F. Fish Immunoglobulins. Biology 5, 45, https://doi.org/10.3390/biology5040045 (2016).

\section{Acknowledgements}

This study is part of M.J. Peixoto PhD thesis. This work has received funding from the European Union's Horizon 2020 research and innovation program under the TNA programme (project ID AE040085) within AQUAEXCEL ${ }^{2020}$ project (652831) to RF, LJM and ROAO for accessing to IATS-CSIC facilities. This output reflects only the author's view and the European Union cannot be held responsible for any use that may be made of the information contained therein. The authors would like to thank M.A. González for her excellent technical assistance during gene expression analyses. 


\section{Author contributions}

M.J. Peixoto wrote the main manuscript text. M.J. Peixoto and R.O.A. Ozório carried out the biochemical analyses and were responsible for Figs 1-3 and the Table 1, 2, S1 and S5. R.O.A. Ozório, L.J. Magnoni and M.J. Peixoto were responsible for the experimental design. R. Ferraz, J. Calduch-Giner and J. Pérez-Sánchez carried out the gene expression analyses and prepared Figs 4, 5 and S1 and Tables S2, S3, S4, S5, S6 and S7. J.F. Gonçalves and M.J. Peixoto were responsible for the coordination and preparation of the in vivo fish trial. R. Pereira was responsible for the seaweed production and processing. All authors reviewed the manuscript.

\section{Competing interests}

The authors declare no competing interests.

\section{Additional information}

Supplementary information is available for this paper at https://doi.org/10.1038/s41598-019-52693-6.

Correspondence and requests for materials should be addressed to R.O.A.O.

Reprints and permissions information is available at www.nature.com/reprints.

Publisher's note Springer Nature remains neutral with regard to jurisdictional claims in published maps and institutional affiliations.

(1) Open Access This article is licensed under a Creative Commons Attribution 4.0 International License, which permits use, sharing, adaptation, distribution and reproduction in any medium or format, as long as you give appropriate credit to the original author(s) and the source, provide a link to the Creative Commons license, and indicate if changes were made. The images or other third party material in this article are included in the article's Creative Commons license, unless indicated otherwise in a credit line to the material. If material is not included in the article's Creative Commons license and your intended use is not permitted by statutory regulation or exceeds the permitted use, you will need to obtain permission directly from the copyright holder. To view a copy of this license, visit http://creativecommons.org/licenses/by/4.0/.

(C) The Author(s) 2019 